\title{
Urgences
}

\section{Jean-Marc Cormier, Poèmes d'amour, Rimouski, Éditeq, 1982.}

\section{Lucien Cimon}

Numéro 7, 2e trimestre 1983

URI : https://id.erudit.org/iderudit/025109ar

DOI : https://doi.org/10.7202/025109ar

Aller au sommaire du numéro

Éditeur(s)

Urgences

ISSN

0226-9554 (imprimé)

1927-3924 (numérique)

Découvrir la revue

Citer ce compte rendu

Cimon, L. (1983). Compte rendu de [Jean-Marc Cormier, Poèmes d'amour,

Rimouski, Éditeq, 1982.] Urgences, (7), 85-87. https://doi.org/10.7202/025109ar

Ce document est protégé par la loi sur le droit d'auteur. L'utilisation des services d'Érudit (y compris la reproduction) est assujettie à sa politique d'utilisation que vous pouvez consulter en ligne.

https://apropos.erudit.org/fr/usagers/politique-dutilisation/
Cet article est diffusé et préservé par Érudit.

Érudit est un consortium interuniversitaire sans but lucratif composé de l’Université de Montréal, l'Université Laval et l'Université du Québec à Montréal. Il a pour mission la promotion et la valorisation de la recherche. https://www.erudit.org/fr/ 


\section{PARUTIONS COMMENTÉES}

POĖMES D'AMOUR, Jean-Marc Cormier, ÉDITEQ, Rimouski, 1982.

Comme s'il n'était plus possible de mourir sans rien dire, la poésie naît, chez nous, comme des cris de mauvais rêves. "Il fait rage ici", entre les deux eaux d'un mauvais alcool, entre chair et ciel, entre cul et Christ. Le rythme est endiablé, les images griffues; les images se succèdent comme des coups de marteau, tantôt pour l'effet, tantôt pour casser la croûte des faux-semblants et pour toucher à l'essentiel, au sensible.

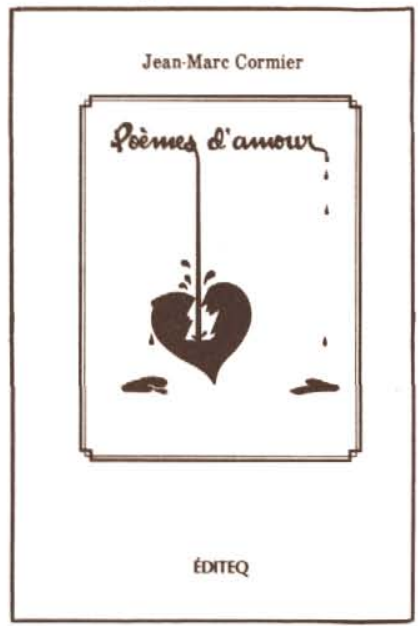

"La vraie poésie est un acte", un acte de départ: un long arrachement à la fascination froide de la ville polluée, corps et esprit, pour ceux qui vivent trop près des égouts. Un départ à la poursuite d'un rêve plein d'eau, plein d'air et plein d'oiseaux, comme le mot Gaspésie. Un geste de combat contre la "défaveur" des "tordeurs de pepsi" qui vivent partout, un mouvement pour fuir les rêves chromés qui crèvent comme des grains de Cracker Jack au moindre coup de dent et qui laissent un arrière-goût de sucre brûlé. Mais on n'échappe pas si facilement à sa condition de "chien écrasé" qui menace comme la crise cardiaque. L'espace n'y peut rien 
ni le paysage qui permet tout au plus d'entendre un peu mieux, de reposer ses yeux et de retrouver le silence de l'absence.

\author{
"Je n'ai jamais vraiment aimé \\ Je suis ce passé bouleversé... \\ Toutes ces haines et toute cette peur" ... (p. 60)
}

Donner un "new look à du vieux stuff". Tous les désespoirs se rencontrent et le pays reste toujours à inventer pour tous ces "frères sales et démunis" qui attendent que la poule aux oeufs d'or accouche d'une planète toute chaude conçue exprès pour eux.

Poèmes d'amour, un recueil intéressant, un livre important pour la région, le meilleur ouvrage de Jean-Marc Cormier. Une poésie qui transgresse les canons Montréalais tant par la forme que par les thèmes, qui évite de plus les étroits corridors de l'édition traditionnelle, qui participe ainsi à la création d'un outil d'expression que l'on peut faire à notre image.

De Westernité (1981) à Poèmes d'amour, peu de temps s'est écoulé mais la poésie de Cormier a fait bien des pas: la forme s'est libérée, l'image s'est raffermie, elle a acquis de l'originalité et de l'assurance: on sent de plus que cette poésie enthousiaste et généreuse chemine lentement vers un plus haut dépouillement et une plus grande maturité. Poésie socialement engagée, aux préoccupations très vastes dans le temps et l'espace, soucieuse des faibles, des maltraités de toutes époques et de tous pays dont elle adopte résolument les habits, l'allure et le langage; poésie qui sait, avec bonheur et naturel se tenir au-dessus des carcans étroits des idéologies de castes, qui se garde du discours propagandiste trop souvent entendu. Ni Godin ni Vanier, encore moins Josée Yvon, Cormier est de plus en plus lui-même, parfois amer, jamais méchant, sans prétention, parfois complaisant: on serait quelquefois tenté de lui reprocher son goût pour l'image volontairement grossière qui se veut choquant mais qui reste en deçà du scandale remuant.
"Le corps du Christ se trempe le bat dans l'alcool
fume du haschisch
et goûte la sodomie"' (p. 27) 
Poésie hypersensible déguisée en Hell's Angel "qui chante et qui danse si naïvement qu'on dirait qu'elle chante et qu'elle danse pendant qu'elle pleure des larmes de sang et qu'elle se tue" (p. 83). Lui reprochera-t-on d'utiliser trop souvent I'accumulation litanique (réf.: le salut sans drapeau)?

Poèmes d'amour illustre encore mieux que Westernité la dualité de l'auteur ou son hésitation à se lancer corps et âme dans une direction où il risquerait de perdre le contrôle de la situation. D'un côté le poète romantique moderne, lyrique, épique parfois.
"J'entends des pas
des pas qui marchent en cadence
et font trembler la terre sur son axe
j'entends comme un respir unique
qui ronfle entre les arbres
300 milliards de souffles ont envahi la terre et je suis envahi par toutes les tornades...",

l'enfant triste, mal aimé qui sait faire des grimaces éloquentes, qui a appris à montrer les poings parce qu'il est blessé, touché et qu'il a peur: peur de perdre l'amour, peur de souffrir comme il voit bien qu'on souffre, peur d'être "buté" pour de bon. De l'autre côté, l'humoriste qui intervient juste à temps pour "dédramatiser" la situation, pour détruire l'envoûtement qui commençait à se créer, pour faire grincer le chant qui commençait à naître,

"Est ainsi

celle que j'aime

en rouleau à prélart"

On n'est pas là pour les cantiques, on n'est pas là pour célébrer la "déprime": on est là pour crier l'urgence du grand ralliement humain, pour affirmer qu'il y a des aliénations qui sont moins confortables que d'autres.

Lucien Cimon 